\title{
Microscale Morphology and Micro-Fluorescence of Oil Sands Extraction Froth from Poorly Processing Ores
}

\author{
V.A. Munoz and R.J. Mikula
}

Advanced Separation Technologies Laboratory, CANMET, Western Research Centre, Natural Resources Canada, Suite A202, Devon, Alberta, T9G 1A8, CANADA

Bitumen extracted from the Athabasca oil sands deposit in northern Alberta is converted to a light sweet crude that currently accounts for more than $25 \%$ of Canada's crude oil requirements. The bitumen extraction process depends upon slurrying the oil sands with water, with the addition of heat and mechanical energy to liberate the bitumen from the mineral matrix. Flotation is then used to concentrate of the bitumen component.

Occasionally bitumen recovery from the oil sands is reduced, or mineral content in the froth is increased, resulting in processing problems downstream. There can be many reasons for poor processing with particular ores, most often they are a high clay content, low bitumen content, or inappropriate water chemistry. Recent experience with a new mine has shown poor processing with a very high grade (high bitumen and low clay content) ore that could not be explained by invoking the usual mechanisms.

Visual observation of the separation cell froth during normal and poor operation showed some distinct differences that were even more striking on a microscopic scale. Samples of froth were collected using a special cryo-probe which was able to rapidly freeze froth samples from a commercial separation cell for later observation. Other samples corresponding to both normal and poor operation were collected from the de-aerated froth for morphology and micro-fluorescence characterization. The morphology of the cryo-probe sampled good and poor ore froths are shownin Fig. 1. The good ore froth was characterized by relatively uniform and small air bubble size distribution, while the poor ore produced a froth with large, irregular bubbles. In the case of the de-aerated froth, the good ore produced a froth with a relatively regular bitumen morphology with water and solids uniformly distributed throughout the continuous bitumen phase. Fluorescence intensity measurements were made only on the bitumen in the froths and this micro-fluorescence data showed a distinct difference between the good and bad ore froths (Table 1). In addition, while the poorly processing ore produces a froth which traps water and solids, with appropriate process aids, it can be converted to be almost indistinguishable from the good froth with similar good recovery and froth quality (Fig. 2).

The combination of micro-fluorescence and morphology of the froth was used to define areas of the mine where poor ores were located. This information was then used to apply appropriate processing aids and normalize recovery and froth quality in order to prevent downstream problems.

Table 1. Comparison of micro-fluorescence intensity for good and bad froths.

\begin{tabular}{|c|c|c|}
\hline & Mean Fluorescence Intensity & Standard Deviation \\
\hline Good Froth Sample 1 & 157 & 19 \\
\hline Good Froth Sample 2 & 100 & 8 \\
\hline Bad Froth Samples 3 & 66 & 10 \\
\hline Bad Froth Sample 4 & 65 & 9 \\
\hline
\end{tabular}




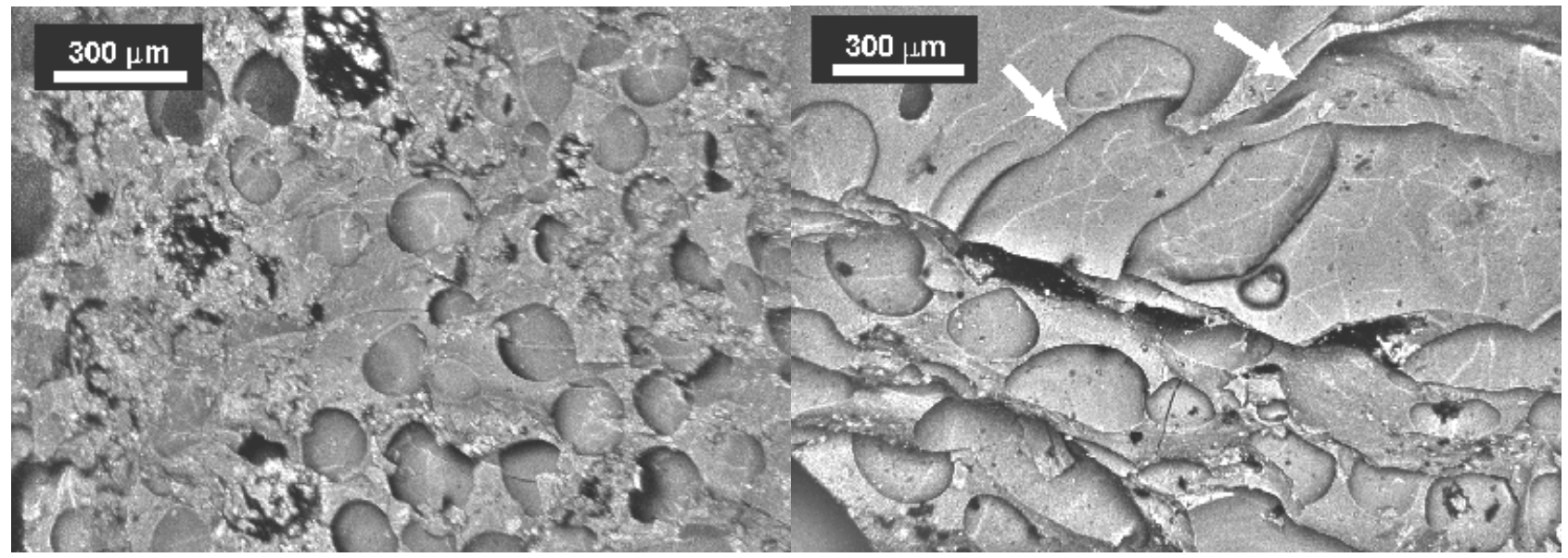

Fig. 1. Confocal micrograph of a frozen bitumen froth from a good (left) and poor (right) processing oil sand ore. The arrows mark very large air bubbles. Fluorescence mode, 468- and 568-nm laser lines.
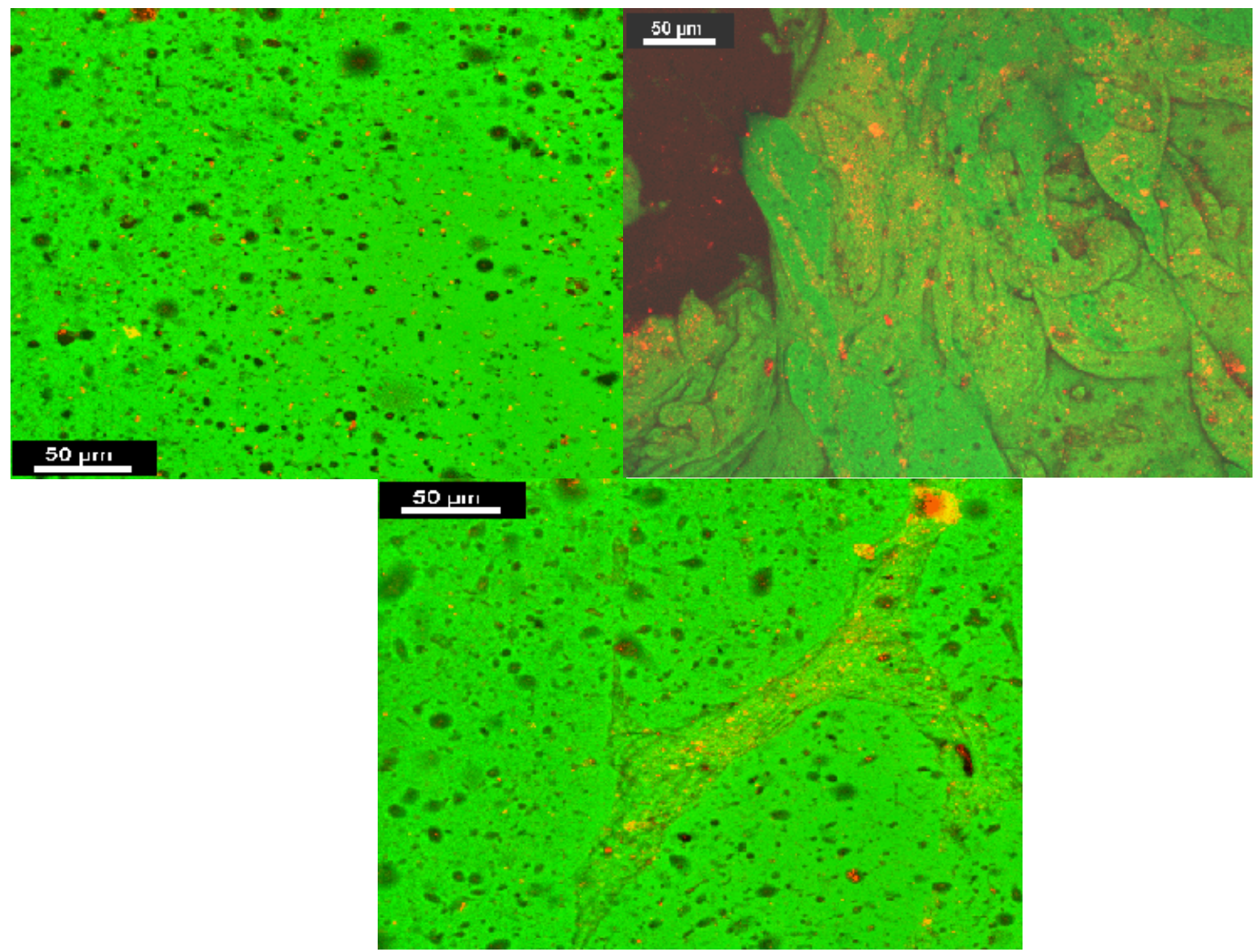

Fig. 2. Confocal micrographs of good (top left) and bad (top right) deaerated froths. This false coloured image was created by simultaneous acquisition in fluorescence and conventional reflected modes. The hydrocarbon is green, the mineral is red, and the water is black. The bitumen in the froth from the poor ore is trapping significantly more water and mineral matter. The bottom center image is froth from a bad ore which has been treated. The result is a froth that is almost indistingishable from the good ore froth with corresponding high bitumen recovery and good froth quality. 